\title{
Application of Two-Stage Hybrid Coronary Revascularization in Multivessel Coronary Artery Disease \\ $\mathrm{Z} \mathrm{Gao}^{1}, \mathrm{~L} \mathrm{Xiao}^{2}, \mathrm{Y} \mathrm{Wang}^{1}, \mathrm{M} \mathrm{Yang}^{2}, \mathrm{Y} \mathrm{Zhang}^{2}, \mathrm{H} \mathrm{Li}^{1}, \mathrm{~J} \mathrm{Zhou}^{2}, \mathrm{Y} \mathrm{Ling}^{3}$
}

\begin{abstract}
Objective: The aim of this study was to explore the efficacy of percutaneous coronary intervention (PCI) with minimally invasive direct coronary artery bypass grafting (MIDCABG) in the treatment for multivessel coronary artery disease (CAD).

Methods: Clinical data was collected from 208 patients with multivessel CAD involving left anterior descending coronary artery (LAD) who underwent PCI between January 2012 and January 2014. There were 16 patients undergoing two-stage hybrid coronary revascularization (HCR) and another 16 paired patients undergoing PCI alone as control. All the patients in HCR group underwent MIDCABG and 3-7 days antiplatelet therapy followed by PCI.

Results: No death and severe complications were observed in 16 patients undergoing HCR, who had longer hospital stay (11.88 \pm 1.15 vs $7.19 \pm 1.11$ days $)$ and higher medical expense $(103186.16 \pm 8743.86$ vs $64645.66 \pm 4929.50$ yuan $)$ compared with PCI group.
\end{abstract}

Keywords: Percutaneous coronary intervention, Drug-eluting stent, Minimally invasive direct coronary artery bypass grafting, Minimally invasive, Hybrid coronary revascularization.

From: ${ }^{1}$ Department of Cardiology, Cangzhou Central Hospital, ${ }^{2}$ Department of Cardiovascular Surgery, Cangzhou Central Hospital, Cangzhou 061001, China, and ${ }^{3}$ Department of Cardiovascular Surgery, the People's Hospital of Peking University Beijing 100044, China.

Correspondence: Dr G Zhisheng, Department of Cardiology, Cangzhou Central Hospital, No 16 Xinhua West Road, Cangzhou 06100, China.

Email: zhishenggaocn@126.com

West Indian Med J 2015

DOI: 10.7727/wimj/2015.425 
During 3-24 months follow-up, there were no death and myocardial infarction in both groups, but an attack of angina occurred in one patient in PCI group who afterwards underwent coronary angiography and second PCI with implantation of drug-eluting stents due to in-stent restenosis.

Conclusions: Two-stage HCR is a safe, effective and minimally invasive method to treat multivessel CAD. 


\section{INTRODUCTION}

In recent decades, percutaneous coronary intervention (PCI) and coronary artery bypass grafting (CABG) play important but different roles in the treatment for coronary artery disease (CAD). Patients with CAD involving left anterior descending coronary artery (LAD) undergoing CABG surgery today receive a left internal mammary artery (LIMA) bypass graft to LAD, which is superior to stent placement during PCI due to high short or long-term patency rate (1). Minimally invasive direct CABG (MIDCABG) is an injury-limited option for patients $(2,3)$. Nowadays saphenous vein graft (SVG) is widely performed in patients with CAD not involving LAD. However, the short or long-term patency rate of SVG is not proved to be superior to that of drug-eluting stent (DES) implantation (4-7). Therefore, hybrid coronary revascularization (HCR), combining MIDCABG and PCI, may obtain the best short or long-term effects in patients with multivessel CAD. HCR can be conducted as a concurrent procedure or as a two-stage: single-stage HCR provides patient with consecutive MIDCABG and PCI, while in two-stage HCR CABG is performed in traditional operating room and PCI as a separate procedure in cardiac catheterization laboratory. Two-stage HCR is widely conducted as no specially equipped operating room or cardiac catheterization laboratory is required. However, the order of procedures and application of antiplatelet drug are controversial (8). In this paper the effectiveness of two-stage HCR to treat multivessel CAD is summarized. 


\section{MATERIALS AND METHODS}

\section{Subjects}

A total of 691 patients undergoing PCI between January 2012 and January 2014 were recruited, including 208 patients with multivessel CAD involving LAD. There were 16 patients undergoing two-stage HCR according to the morphology and structure of lesions. Another 16 patients undergoing PCI alone who had comparable age, gender, lesions and admission time to the patients in HCR group were selected as control (Table 1). This study was conducted in accordance with the declaration of Helsinki. This study was conducted with approval from the Ethics Committee of Cangzhou Central Hospital. Written informed consent was obtained from all participants.

\section{Surgical operation}

Considering the necessity of dual antiplatelet therapy after PCI and the risk of hemorrhagic complications in the patients during MIDCAB, all the patients in HCR group stopped using antiplatelet drugs three days before surgery. $100 \mathrm{mg}$ of aspirin and $75 \mathrm{mg}$ of clopidogrel were taken orally once per day from the second day after surgery; $300 \mathrm{mg}$ of clopidogrel was taken in the morning of PCI at a draught. PCI was performed 3-7 days after surgery and the patients stayed in hospital during the whole procedure.

MIDCABG: Left anterior small thoracotomy was performed in the patient after general anesthesia, and then endotracheal double lumen endotracheal intubation was performed. The patient was placed in a supine position, and the left chest was 
30-degree bolstered up. Electrode slices were attached onto right front and left rear chest wall and connected with automated external defibrillator. An $6 \mathrm{~cm}$ incision was done at the fourth intercostal space of left front chest and one-lung ventilation was conducted. The suspensory internal mammary artery retractor system (FEHLING-Instrument) was placed through the incision to open the rib and elevate the chest wall, providing good operation view. LIMA was isolated from the superior border of the first rib till the fifth rib. The branches of LIMA were clipped using pen type titanium clamp (FEHLING-Instrument). After LIMA isolation, pericardium was cut open, the LAD anastomosis site was determined, LAD was isolated, and heparinization $(1 \mathrm{mg} / \mathrm{kg})$ was performed. The distal end of LIMA was mutilated and the blood flow in LIMA was monitored. Then the suspensory system was removed, the rib retractor was placed and pericardium was suspended. A heart stabilizer was utilized to fix LAD, an incision was made on coronary artery and an artery shunt was inserted into it, and LIMA-LAD anastomosis was done using 8-0 prolene wire. After anastomosis, ultrasonic blood flow meter was employed to monitor blood flow volume through LIMA graft. At last, protamine was administrated to neutralize heparin, a chest drainage tube was placed and sternal closure was performed.

PCI: PCI was performed through the right radial artery or brachial artery patients in patients from PCI group, while in HCR group PCI was done through the right femoral artery to facilitate LIMA angiography and monitor arterial graft patency during surgery. DES was implanted in patients of both groups during PCI. 


\section{Follow-up}

Patients received telephone or outpatient follow-up after operation.

\section{Statistical analysis}

Data was analyzed with SPSS17.0. Measurement data was presented as means \pm SE. The comparison between groups utilized paired Student's t-test. The comparison of enumeration data used Chi-squared test. $P<0.05$ was considered statistically significant.

\section{RESULTS}

\section{Postoperative hospitalization}

Postoperative hospitalization was summarized in Table 2. There were no death, stroke, perioperative MI, kidney failure, severe bleeding (required blood infusion) and wound complications. LIMA grafts in HCR group were patent shown by angiography during PCI. Patients in HCR group had significantly longer hospital stay $(11.88 \pm 1.15$ vs $7.19 \pm 1.11$ days), distinctly higher medical expense (103186.16 \pm 8743.86 vs $64645.66 \pm 4929.50$ yuan $)$ and less stents $(1.81 \pm 0.66$ vs $3.00 \pm 0.73)$ implanted in each patient compared with that of PCI group.

\section{Follow-up}


During 3-24 months follow-up (median 8), an attack of angina occurred in one patient in PCI group who afterwards underwent coronary angiography and second PCI with implantation of DES due to in-stent restenosis in LAD. No death was observed.

\section{DISCUSSIONS}

PCI is a minimally invasive procedure widely used to treat the stenotic coronary arteries in recent decades, which allows patients to recover quickly. With the application of DES, in-stent restenosis rate significantly declines. ${ }^{5}$ However, the main disadvantage of PCI is the special requirement for morphology and structure of lesions. The success rate of PCI for severe calcified lesions, chronic total occlusion and diffuse lesions is low and the incidence of complications is high. Complexity of lesion morphology reduces PCI success (9).

CABG has much less strict requirements for lesions and has advantages over PCI for complex multivessel CAD, left main CAD and CAD complicated by diabetes (10, 11). Additionally, CABG is much superior to PCI in treating more complex CAD (9). However, $\mathrm{CABG}$ also has prominent disadvantages, such as large surgical trauma, slow postoperative recovery, long hospital stay, high short and long-term vein graft stenosis and occlusion rate, which make it hard for patients to accept the surgery. The MIDCABG procedure involves grafting the LIMA to the LAD through a much smaller surgical incision, which avoids the disadvantages of traditional CABG and maintains high long-term patency of arterial graft $(2,3)$. However, MIDCABG is not a good option for non-LAD lesions. Therefore, combining the benefits of LIMA-LAD 
graft with less-invasive PCI to treat non-LAD lesions may provide a best strategy for multivessel CAD.

HCR procedure was first reported with good efficacy by Angelini GD in 1996 (12). In 2013, Shen et al showed that the incidence of main adverse cardiovascular and cerebrovascular events in 141 patients undergoing single-stage HCR was significantly lower than that of patients undergoing traditional CABG or PCI in three-year follow-up study (13). Single-stage HCR is performed in a specially designed hybrid operating room; while two-stage HCR is widely conducted as no specially equipped operating room or cardiac catheterization laboratory is required.

In two-stage HCR, the order of procedures is controversial. Performing PCI after CABG may be a better strategy, as dual antiplatelet therapy is required for at least one year after PCI, while withdrawal of antiplatelet drugs and neutralisation of heparin after MIDCABG may cause in-stent thrombosis (14). PCI following aggressive antiplatelet therapy after MIDCABG may increase the safety of stent placement and the LIMA graft patency can be verified at the time of PCI. All the patients underwent PCI after CABG in our study. The main disadvantage of this order of operations may be that in the event of PCI complication or failure, a second, higher-risk operation needs to be performed.

According to the recovery of 16 patients undergoing HCR in our study, two-stage HCR has higher security, lower incidence of complications and better short-term efficacy. Patients in HCR group had longer hospital stay and higher medical expense compared with patients in PCI group, which was similar to the report 
from Halkos ME et al that medical expense was higher for patients undergoing HCR than that of patients undergoing off-pump CABG (15). In our study, PCI was difficult to treat LAD lesions in patients undergoing HCR, unless special equipment and operation, such as rotational atherectomy, guiding catheter deep insertion or 5-in-6 double catheter technique, multiple balloons and stents are used, which, however, increases the operation risk and medical cost. Due to the optimal combination in HCR (DES replace vein grafts, arterial grafts replace DES), HCR may has lower rate of long-term target vessel revascularization than that of PCI and comparable long-term efficacy to that of traditional CABG $(16,17)$. Thus the expense and social cots it saved may compensate longer hospital stay and higher medical cost.

In conclusion, two-stage $\mathrm{HCR}$ is a minimally invasive method to treat multivessel CAD due to the scientific support, less demands on operation room, good efficacy and rapid recovery. Long-term efficacy of HCR requires further confirmation and a large-scale, multicenter, long-term follow-up study.

\section{Conflict of interest}

All authors have no conflict of interest regarding this paper.

\section{REFERENCES}

1. Jaffery Z, Kowalski M, Weaver WD, Khanal S. A meta-analysis of randomized control trials comparing minimally invasive direct coronary bypass grafting versus percutaneous coronary intervention for stenosis of the proximal left 
anterior descending artery. Eur J Cardiothorac Surg 2007; 31: 691-7.

2. Iribarne A, Easterwood R, Chan EY, Yang J, Soni L, Russo MJ et al. The golden age of minimally invasive cardiothoracic surgery: current and future perspectives. Future Cardiol 2011; 7: 333-46.

3. Deo SV, Sharma V, Shah IK, Erwin PJ, Joyce LD, Park SJ. Minimally invasive direct coronary artery bypass graft surgery or percutaneous coronary intervention for proximal left anterior descending artery stenosis: a meta-analysis. Ann Thorac Surg 2014; 97: 2056-65.

4. Cao C, Ang SC, Wolak K, Peeceeyen S, Bannon P, Yan TD. A meta-analysis of randomized controlled trials on mid-term angiographic outcomes for radial artery versus saphenous vein in coronary artery bypass graft surgery. Ann Cardiothorac Surg 2013; 2: 401-7.

5. Weisz G, Leon MB, Holmes DR Jr, Kereiakes DJ, Clark MR, Ellis SG et al. Two-year outcomes after sirolimus-eluting stent implantation: results from the Sirolimus-Eluting Stent in de Novo Native Coronary Lesions (SIRIUS) trial. J Am Coll Cardiol 2006; 47: 1350-5.

6. Kim KB, Cho KR, Jeong DS. Midterm angiographic follow-up after off-pump coronary artery bypass: serial comparison using early, 1-year, and 5-year postoperative angiograms. J Thorac Cardiovasc Surg 2008; 135: 300-7.

7. Hannan EL, Racz M, Holmes DR, Walford G, Sharma S, Katz S et al. Comparison of coronary artery stenting outcomes in the eras before and after the introduction of drug-eluting stents. Circulation 2008; 117: 2071-8. 
8. Harskamp RE, Zheng Z, Alexander JH, Willams JB, Xian Y, Halkos ME et al. Status quo of hybrid coronary revascularization for multi-vessel coronary artery disease. Ann Thorac Surg 2013; 96: 2268-77.

9. Serruys PW, Morice MC, Kappetein AP, Colombo A, Holmes DR, Mack MJ et al. Percutaneous coronary intervention versus coronary artery bypass grafting for severe coronary artery disease. N Engl J Med 2009; 360: 961-72.

10. Efird JT, O'Neal WT, Davies SW, Kennedy WL, Alger LN, O'Neal JB et al. Long-Term Mortality of 306,868 Patients with Multi-Vessel Coronary Artery Disease: CABG versus PCI. Br J Med Med Res 2013; 3: 1248-57.

11. Sipahi I, Akay MH, Dagdelen S, Blitz A, Alhan C. Coronary artery bypass grafting vs percutaneous coronary intervention and long-term mortality and morbidity in multivessel disease: meta-analysis of randomized clinical trials of the arterial grafting and stenting era. JAMA Intern Med 2014; 174: 223-30.

12. Angelini GD, Wilde P, Salerno TA, Bosco G, Calafiore AM. Integrated left small thoracotomy and angioplasty for multivessel coronary artery revascularization. Lancet 1996; 347: 757-8.

13. Shen L, Hu S, Wang H, Xiong H, Zheng Z, Li L et al. One-stop hybrid coronary revascularization versus coronary artery bypass grafting and percutaneous coronary intervention for the treatment of multivessel coronary artery disease: 3-year follow-up results from a single institution. J Am Coll Cardiol 2013; 61: 2525-33.

14. Delhaye C, Sudre A, Lemesle G, Vanesson L, Koussa M, Fayad G et al. Hybrid 
revascularization, comprising coronary artery bypass graft with exclusive arterial conduits followed by early drug-eluting stent implantation, in multivessel coronary artery disease. Arch Cardiovasc Dis 2010; 103: 502-11.

15. Halkos ME, Ford L, Peterson D, Bluestein SM, Liberman HA, Kilgo P et al. The impact of hybrid coronary revascularization on hospital costs and reimbursements. Ann Thorac Surg 2014; 97: 1610-5, discussion 1615-6.

16. Adams C, Burns DJ, Chu MW, Jones PM, Shridar K, Teefy P et al. Single-stage hybrid coronary revascularization with long-term follow-up. Eur J Cardiothorac Surg 2014; 45: 438-42.

17. Harskamp RE, Puskas JD, Tijssen JG, Walker PF, Liberman HA, Lopes RD et al. Comparison of hybrid coronary revascularization versus coronary artery bypass grafting in patients $\geq 65$ years with multivessel coronary artery disease. Am J Cardiol 2014; 114: 224-9. 
Table 1: Comparison of general data between two groups

\begin{tabular}{|c|c|c|c|}
\hline Item & HCR group $(n=16)$ & PCI group $(n=16)$ & $P$ value \\
\hline Gender & & & -- \\
\hline Male & 9 & 9 & \\
\hline Female & 7 & 7 & \\
\hline Age & $66.3 \pm 6.3$ & $65.5 \pm 6.5$ & 0.097 \\
\hline Diabetes & 10 & 6 & 0.289 \\
\hline Hypertension & 13 & 15 & 0.600 \\
\hline Low density lipoprotein cholesterol (mmol/L) & $3.32 \pm 1.00$ & $3.51 \pm 0.69$ & 0.412 \\
\hline Triglyceride (mmol/L) & $2.88 \pm 1.30$ & $2.50 \pm 0.95$ & 0.327 \\
\hline Old myocardial infarction (MI) & 5 & 2 & 0.394 \\
\hline Grading of angina pectoris (CCS) & & & 0.504 \\
\hline I & 0 & 0 & \\
\hline
\end{tabular}


IV

Left ventricular function (ejection fraction) 
Table 2: Comparison of postoperative data between two groups

\begin{tabular}{|c|c|c|c|}
\hline Death in hospital & 0 & 0 & -- \\
\hline Severe bleeding(required blood infusion) & 0 & 0 & -- \\
\hline Perioperative MI & 0 & 0 & -- \\
\hline Hospital stay(day) & $11.88 \pm 1.15$ & $7.19 \pm 1.11$ & $<0.001$ \\
\hline Medical expense(yuan) & $103186.16 \pm 8743.86$ & $64645.66 \pm 4929.50$ & $<0.001$ \\
\hline Stroke & 0 & 0 & -- \\
\hline
\end{tabular}

Note: --no value 